\title{
BUDAYA SEKOLAH DALAM MEWUJUDKAN SEKOLAH SEHAT NASIONAL DI SD MUHAMMADIYAH 1 KETELAN SURAKARTA
}

\begin{tabular}{l}
\hline INFO ARTIKEL \\
\hline Riwayat Artikel: \\
Diterima: 26-Maret-2021 \\
Disetujui: 31-Maret-2021 \\
\end{tabular}

\section{Kata Kunci:}

Budaya Sehat Sekolah Dasar

\author{
Merinda Tria Vilian ${ }^{1}$, Minsih $^{2}$ \\ Prodi Pendidikan Guru Sekolah Dasar, Universitas Muhammadiyah Surakata ${ }^{1,2}$ \\ Merindavillian98@gmail.com ${ }^{1}, \min 139 @$ ums.ac.id $^{2}$
}

\begin{abstract}
ABSTRAK
Abstrak: Tujuan penelitian yaitu untuk mendiskripsikan budaya sekolah, faktor pendukung dan penghambat, serta peran siswa dalam mewujudkan sekolah sehat nasional di (sekolah dasar) SD Muhammadiyah 1 Ketelan Surakarta.Narasumber dalam penelitian ini yaitu Kepala Sekolah, Wakil Kepala Sekolah (WKS) kurikulum, siswa, dan petugas unit kesehatan sekolah (UKS). Jenis penelitian menggunakan pendekatan kualitatif deskriptif dengan desain fenomenologi. Pengumpulan data dilakukan dengan teknik wawancara mendalam, observasi, dan dokumentasi. Pengujian keabsahan data menggunakan triangulasi sumber. Penelitian menggunakan model interaktif sebagi teknik analisis yakni reduksi data, penyajian data, dan penarikan kesimpulan. Hasil penelitian menunjukkan bahwa sekolah telah mewujudkan sekolah sehat nasional melalui budaya sekolah dengan didasarkan pada kebijakan sekolah dan berpartisipasi seluruh warga sekolah dalam berperilaku hidup bersih dan sehat (PHBS). Kegiatan siswa mulai dari mencuci tangan, mengkonsumsi makanan sehat, ibadah bersama, berolahraga, membuang sampah pada tempatnya, sekolah bebas rokok, menjaga kebersihan toilet, piket kelas, kerja bakti, lomba kebersihan kelas, dan pemeriksaan jentik nyamuk. Faktor pendukung terdiri dari warga sekolah yang aktif, sarana dan prasarana memadai, kerjasama dengan pihak profesional. Sedangkan faktor penghambat yaitu kurangnya pembiasaan hidup sehat dan banyaknya pedagang jajanan sekolah yang kualitasnya belum sesuai. Peran siswa dalam penyelenggaraan sekolah sehat nasional yaitu menjaga kebersihan lingkungan sekolah, kelas, dan diri pribadi
\end{abstract}

\begin{abstract}
The research objective is to describe the school culture, supporting and inhibiting factors, as well as the role of students in realizing a national healthy school in the Muhammadiyah 1 Ketelan elementary school, Surakarta. Resource persons in this study were the Principal, Deputy Principal of the curriculum, students, and school health unit officers. This type of research uses a descriptive qualitative approach with a phenomenological design. The research data collection was carried out by using in-depth interview techniques, observation and documentation. Testing the validity of the data using source triangulation. The study used an interactive model as an analysis technique, namely data reduction, data presentation, and drawing conclusions. The results showed that the school has realized a national healthy school through school culture based on school policy and the participation of all school members in a clean and healthy lifestyle. Student activities start from washing hands, consuming healthy food, praying together, exercising, disposing of garbage in its place, smoking-free schools, keeping toilets clean, class pickets, community service, class cleaning competitions, and checking mosquito larvae. Supporting factors consist of active school members, adequate facilities and infrastructure, cooperation with professionals. Meanwhile, the inhibiting factors are the lack of healthy living habits and the large number of school snack traders whose quality is not suitable. The role of students in organizing a national healthy school is to maintain the cleanliness of the school environment, class, and themselves.
\end{abstract}

\section{A. LATAR BELAKANG}

Satuan pendidikan yang berfungsi meningkatkan ilmu pengetahuan, sikap, dan keterampilan generasi bangsa sebagai bekal taraf hidup menjadi yang lebih baik adalah pendidikan formal atau sekolah. Menurut (Rochmah, 2018); (Irwandi et al., 2016) menyatakan bahwa tujuan sekolah yaitu mempersiapkan anak didik dalam meningkatkan pengetahuan, sikap, dan keterampilan untuk mencapai taraf dan kualitas hidupnya di lingkungan 
masyarakat. Pembentukan kepribadian anak sangat penting dilakukan oleh semua jenjang sekolah, terutama pada sekolah dasar yang digunakan sebagai pondasi awal dalam mewujudkan pribadi anak untuk masa yang akan datang. Anak yang memiliki kepribadian baik, maka akan berdampak pada prestasi belajar anak yang baik pula. Menurut Cvencek, Fryberg, Covarrubias, \& Meltzoff (2017) menyatakan bahwa adanya keterkaitan antara kerpibadian dan harga diri siswa di sekolah dasar terhadap pencapaian prestasi akademik anak di masa depan.

Salah satu bentuk penanaman kepribadian anak diberikan melalui pendidikan perilaku hidup yang sehat, baik dalam bentuk sosial, fisik, dan psikis. Penanaman pribadi tersebut dapat dimulai sejak dini di bangku sekolah melalui berbagai program pembelajaran (Yufiarti et al., 2019). Pernyataan yang sama dari Kandou \& Caroline (2019) menyarankan bahwa agar sekolah menyediakan lebih banyak fasilitas yang dapat mendukung siswa untuk menerapkan perilaku hidup bersih dan sehat seperti adanya program maupun kebijakan sekolah sehat. Sekolah sehat merupakan lingkungan sekolah bersih, rindang, hijau, nyaman, dan aman, serta memiliki warga sekolah yang aktif, sehat, maupun berperilaku hidup bersih dan sehat (Utama et al., 2018). Undang-Undang Nomor 36 Tahun 2009 Pasal 79 tentang kesehatan telah menegaskan bahwa kebijakan kesehatan sekolah diadakan untuk meningkatkan perilaku hidup sehat pada peserta didik dengan tujuan mendorong semangat siswa untuk mengembangkan diri serta mampu mencapai generasi bangsa yang berkualitas. Cara membentuk perilaku hidup sehat siswa adalah dengan condisioning atau kebiasaan (Sulastri, Purna, \& Suyasa, 2014: 103). Menanamkan perilaku hidup sehat pada peserta didik perlu adanya suatu pembiasaan-pembiasaan atau budaya sekolah.

Budaya sekolah merupakan suatu pembiasaan, simbol, dan norma yang dapat mempengaruhi perilaku warga sekolah. Menurut Lee \& Louis (2019) mengatakan bahwa budaya sekolah yang kuat mampu membawa perubahan besar untuk sekolah yang berkelanjutan dan kinerja warga sekolah. Pernyataan yang sama dari (Maryamah, 2016); (Wiwik et al., 2016) mengatakan bahwa budaya sekolah merupakankumpulan nilai yang digunakan sebagai dasar untuk berperilaku, tradisi, membentuk kepribadian dan keyakinan oleh semua warga sekolah tanpa terkecuali yang secara tidak langsung tercermin dalam tujuan sekolah. Sehingga budaya sekolah yang memiliki antusias tinggi terhadap menciptakan sekolah sehat, maka akan berdampak pada pembentukan kepribadian warga sekola dengan berperilaku hidup bersih dan sehat yang baik pula. Kepala sekolah sebagai pemimpin memiliki tanggungjawab dalam menerapkan kebijakan program sekolah sehat. Lee et al. (2018) membuktikan bahwa penerapan kebijakan sekolah sehat sangat berpengaruh terhadap kesehatan seluruh warga sekolah. Selain itu, beliau juga menambahkan bahwa kebijakan sekolah sehat juga dapat meningkatkan kondisi kesehatan lingkungan sekolah dan memberikan efek positif bagi proses belajar mengajar.Penelitian yang sama dari Zubaidah, Ismanto, \& Sulasmono (2017) menyatakan bahwa program sekolah sehat dapat berjalan dengan baik apabila ada apresiasi dan partisipasi baik dari seluruh warga sekolah yang tercermin dalam budaya sekolah. Sekolah satu dengan lainnya telah memiliki karakterstik dan budaya masing-masing yang harus dikembangkan.Sehingga adanya keberagaman budaya tersebut menunjukkan adanya perbedaan yang harus dijunjung tinggi baik itu positif maupun kurang budaya di dalam sekolah.

Pelaksanaan program sekolah sehat dengan membudayakan diri untuk cinta akan kebersihan dan kesehatan terhadap seluruh warga sekolah. Hermiyanty, Salmawati, \& Oktavian (2016) membuktikan bahwa sekolah yang bersih dan sehat (SBS) adalah sekolah dimanaseluruh warganya telah memiliki tingkat kebersihan yang baik, dan terciptanya lingkungan sekolahyang berkategori bersih, segar, rapi, tertib,indah, dan aman. Rendahnya pengetahuan mengenai perilaku hidup sehat juga sangat berpengaruh dalam praktek atau pengimplementasikan perilaku hidup sehat. Menurut Kusumawardani, Rekawati, \& Fitriyani (2019: 240) bahwa PHBS harus dilaksanakan sejak sekolah dasar agar praktik gaya hidup sehat dapat bertahan hingga dewasa. Vivas et al. (2010) menambahkan bahwa memiliki sumber daya dan faslitas yang memadai praktik kebersihan sekolah sangat dipengaruhi oleh pengetahuan dan sikap siswa terhadap kebersihan.

Berdasarkan observasi awal oleh peneliti di kegiatan PLP II (pengenalan lapangan persekolahan (Agustus, 2019)) dan KKN (kuliah kerja nyata (Januari-Maret, 2020)) banyak ditemui perilaku siswa yang menunjukkan kurangnya kebiasaan PHBS. Kebiasaan PHBS bisa dilihat dari gerakan mencuci tangan, membuang sampah pada tempatnya, makan makanan yang bergizi, kebersihan lingkungan kelas maupun sekolah dan lain sebagainya. Sehingga temuan awal peneliti menunjukkan bahwa belum sepenuhnya setiap sekolah dasar (SD) menerapkan perilaku hidup sehat sebagai budaya sekolah.

Peran warga sekolah dalam pembiasaan perilaku hidup sehat sangat berdampak pada pencapaian tujuan sekolah sehat. Seperti SD Muhammadiyah 1 Ketelan Surakarta yang dituliskan pada artikel sekolah bahwa "Prestasi berhasil diraih oleh SD Muhammadiyah 1 Ketelan Surakarta dengan juara pertama dalam Lomba Sekolah Sehat (LSS) yang diberikan langsung dari Dinas Pendidikan dan Kebudayaan di Provinsi Jawa Tengah pada tahun 2019" (Dikutip dari Sdmuh1 solo.com, dengan artikel Dinobatkan Sekolah Sehat Terbaik Tingkat Jawa Tengah, 2019). SD Muhammadiyah 1 Ketelan Surakarta mengintegrasikan pendidikan kesehatan termasuk cara hidup yang bersih dan sehat dalam mata pelajaran (Dikutip dari Sdmuh1 solo.com,dengan artikel Ganjar Pranowo Berikan Dukungan Sekolah Sehat Nasional, 2020). Penghargaan tersebut menjadikan Perilaku Hidup Bersih dan 
Sehat (PHBS) sebagai kebiasaan atau budaya sekolah yang penting untuk dilakukakan oleh semua warga sekolah dalam mewujudkan sekolah sehat. Selain itu, mendorong kesadaran siswa terhadap pentingnya berprestasi dan menjaga lingkungan sekolah tetap bersih serta pembiasaan diri untuk hidup bersih dari sejak dini kepada siswa (Dikutip dari Sdmuh1 solo.com, dengan artikel Sri Sayekti Ajak Hidup Sehat dan Berprestasi, 2019). Penanaman untuk berperilaku hidup sehat sejak dini disekolah, maka diharapkan perilaku tesebut dapat mewujudkan sekolah sehat dan akan terbawa hingga dewasa nanti. Pembinaan lingkungan sekolah yang sehat dapat melatih siswa dan warga sekolah lainnya untuk menerapkan hidup sehat (Pradipta, 2017: 21).

Berdasarkan pemaparan masalah di atas dan belum pernah adanya hasil penelitian terkait dengan budaya sekolah dalam mewujudkan sekolah sehat nasional terutama di SD Muhammadiyah 1 Ketelan Surakarta telah mendorong peneliti untuk melakukan kajian yang lebih mendalam.Sehingga tujuan penelitian ini yaitu untuk mendeskripsikan budaya sekolah dalam mewujudkan sekolah sehat nasional, dan faktor-faktor yang mempengaruhi, serta peran siswa dalam mewujudkan sekolah sehat nasional di SD Muhammadiyah 1 Ketelan Surakarta.

\section{B. METODE PENELITIAN}

Penelitian ini termasuk ke dalam jenis penelitian kualitatif deskripif dengan desain fenomenologi (Creswell, 2014). Lokasi penelitian yaitu SD Muhammadiyah 1 Ketelan Surakarta yang terletak di jalan Kartini, Ketelan, Kecamatan Banjarsari, Kota Surakarta, Jawa Tengah. Narasumber dalam penelitian ini yaitu Kepala Sekolah sebagai informan satu, Wakil Kepala Sekolah bagian Kurikulum sebagai informan dua, Petugas UKS sebagai informan tiga, dan siswa sebagai informan empat.

Teknik wawancara, observasi, dan dokumentasi digunakan untuk mengumpulkan data oleh peneliti. Wawancara mendalam dilakukan terhadap seluruh narasumber, dimana data hasil wawancara dibandingkan dengan data observasi dan dokumentasi yang dilakukan peneliti. Triangulasi sumber digunakan sebagai pengujian keabsahan data untuk menemukan data yang valid dan kredibel. Teknik analisis data mengacu pada Miles and Huberman dalam Sugiyono (2015: 246-253) yang terdiri dari: a) Reduksi data dimana data mentah hasil pengumpulan direduksi oleh peneliti sesuai dengan fokus penelitian, b) penyajian data dilakukan dalam bentuk teks secara narasi, dimana hasil penelitian dibandingkan dengan teori dan penelitian relevan, c) Conclusion Drawing yaitu berdasarkan hasil perbandingan akan ditarik kesimpulan mengenai budaya sekolah dalam mewujudkan sekolah sehat nasional di SD Muhammadiyah 1 Ketelan Surakarta

\section{HASIL DAN PEMBAHASAN}

Berdasarkan teknik pengumpulan data yang dilakukan penelitidi SD Muhammadiyah 1 Ketelan Surkarta, peneliti menemukan bahwasannya adanya keberhasilan budaya sekolah dalam mewujudkan sekolah sehat nasional dan dipengaruhi oleh beberapa faktor, serta adanya wujud nyata peran siswa dalam mewujudkan sekolah sehat nasional. Adapun penjelasan mengenai hasil penelitian sebagai berikut:

\section{Budaya Sekolah dalam mewujudkan Sekolah Sehat Nasional di SD Muhammadiyah 1 Ketelan Surakarta.}

Keberhasilan budaya sekolah dalam mewujudkan sekolah nasional telah didasarkan pada empat komponen kebijakan sekolah, partisipasi aktif dari seluruh warga sekolah terutama oleh siswa. Hasil penelitian juga menunjukkan bentuk kegiatan dari program sekolah sehat diantaranya: UKS (Unit Kesehatan Sekolah), Kantin Sehat, E- Money, bank sampah, Green House dan BUMS, serta pembiasaan diri melalui budaya sekolah. Hasil wawancara budaya sekolah dalam mewujudkan sekolah sehat nasional dapat dilihat pada tabel 1.

Tabel 1. Ringkasan Hasil Wawancara Budaya Sekolah dalam Mewujudkan Sekolah Sehat Nasional

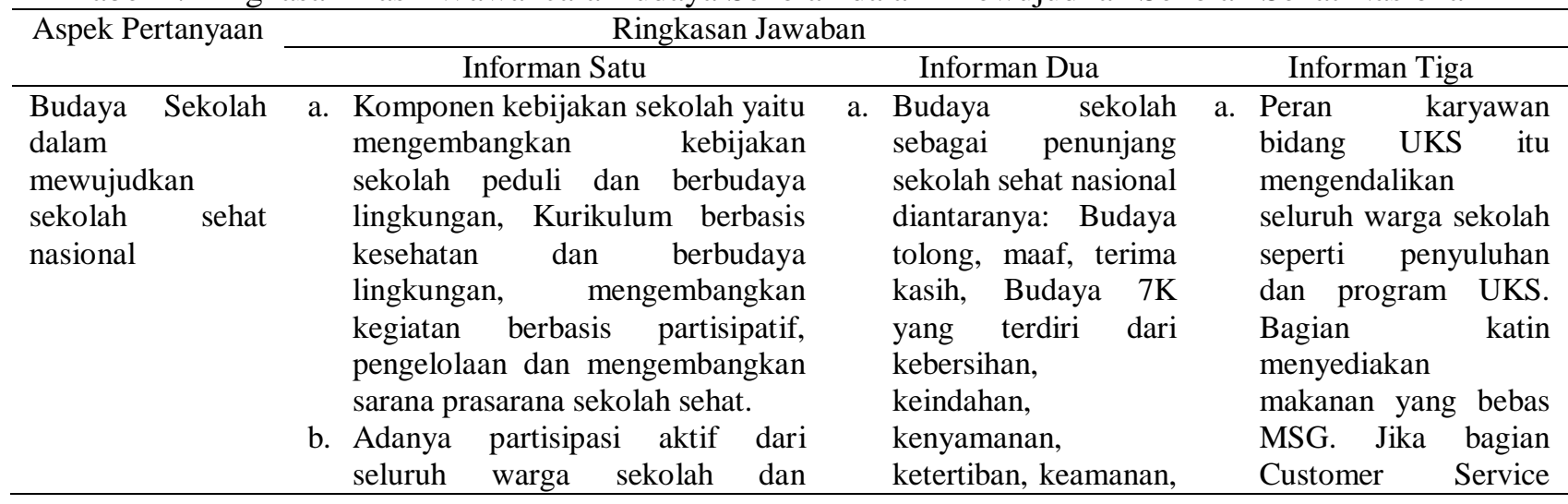


penanggungjawab di semua bentuk kegiatan sekolah sehat. kerindangan, dan

kekeluargaan, serta

Budaya PHBS.

b. Bentuk kegiatan yang dimaksud yaitu UKS, Kantin Sehat, EMoney, bank sampah, Green House dan BUMS.

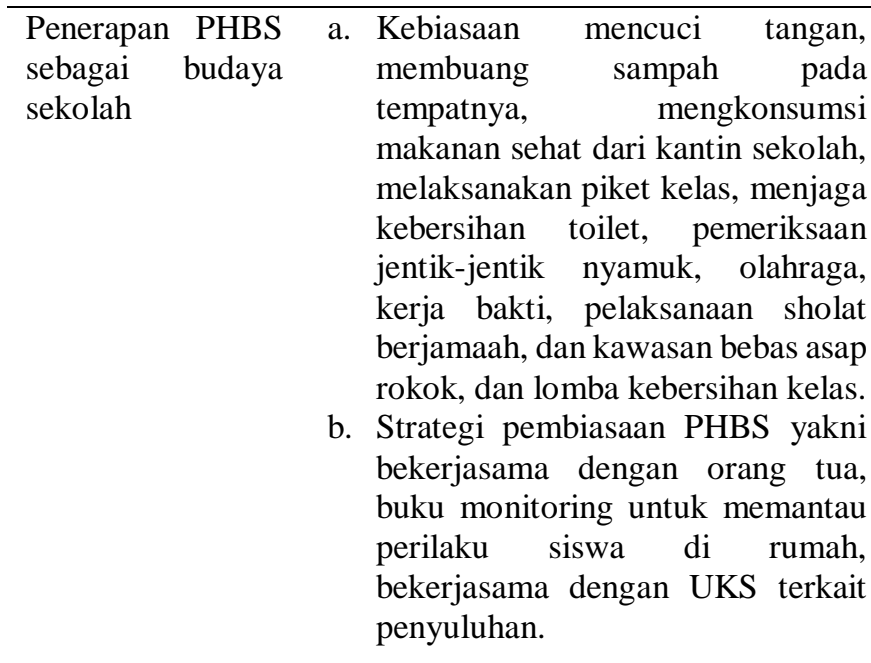

membuang sampah pada tempatnya, piket kelas sesuai jadwal sholat berjamaah berolahraga bersama setiap hari jum'at, mengkonsumsi makanan sehat di kantin sekolah, menjaga kebersihan toilet, pemeriksaan jentik-jentik.

b. Guru memiliki tanggung jawab untuk mengintegrasikan pembelajaran dengan PHBS, Buku monitoring.

\section{a. Mencuci}

lebih fokus pada kebersihanlingkungan, mendisiplinkan siswa untuk menjaga kebersihanya.

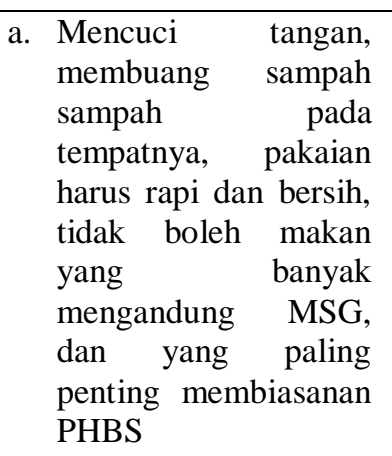

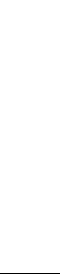




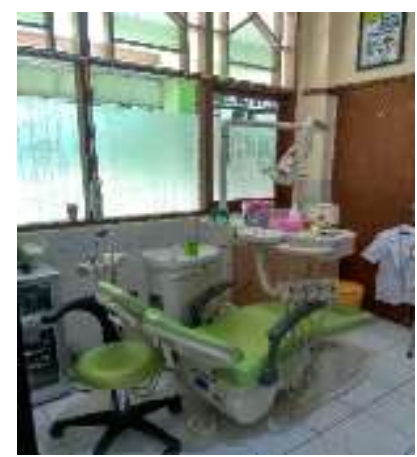

Gambar 1. Ruang UKS

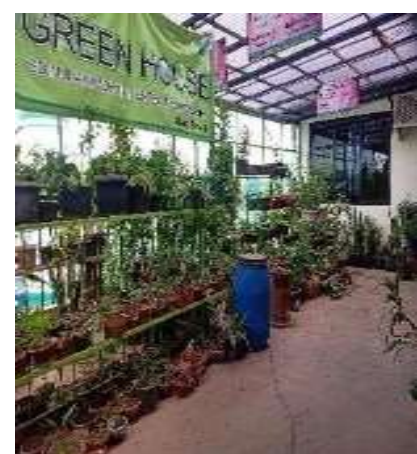

Gambar 2. Green House

Penelitian yang sama dari Taryatman (2016) menunjukkan kegiatan dalam program sekolah sehat seperti menerapkan beberapa indikator bersih dan sehat, mencuci tangan, mengambil makanan sehat, olahraga taratur dan terukur, tidak merokok, membuang sampah ke tempat sampahnya, dll. Penelitian serupa dari Bur \& Septiyanti (2020) yang menyebutkan bentuk kegiatan sekolah sehat seperti melakukan penyuluhan, pendampingan, praktik mandiri PHBS, dan pengadaan sarana \& prasarana sekolah penunjang sekolah sehat. Selain itu, pengintegrasian budaya sekolah dalam mencapai sekolah sehat nasional tercermin dengan adanya budaya tolong, maaf, terima kasih, 7K (kebersihan, ketertiban, keamanan, kerindangan, keindahan, kenyamanan, dan kekeluargaan) dan PHBS. Pernyataan yang sama dari Budiarti \& Sriawan (2017) mengatakan bahwa pelaksanaan budaya tolong, maaf, terima kasih, 7K dan PHBS dapat meningkatkan keamanan sekolah, kesadaran siswa terhadap pentingnya kebersihan lingkungan, meningaktkan disiplin warga sekolah, menciptakan keindahan yang rapi dan tertata, serta hubungan antar warga sekolah semakin baik.

Mewujudkan sekolah sehat dan peduli lingkungan hidup tercermin dari beberapa kebiasaan siswa sebagai berikut: a) mencuci tangan dengan menggunakan air yang mengalir serta menggunakan sabun. b) mengkonsumsi makanan sehat dari kantin sekolah. c) sholat berjamaah baik guru dan siswa. d) berolahraga secara teratur. e) membuang sampah ketempat sampah yang terpilah. f) lingkungan sekolah yang bebas asap rokok. g) menjaga kebersihan toilet. h) piket kelas sesuai masing-masing jadwal siswa. i) pemeriksaan jentik-jentik nyamukyang dilakukan seminggu sekali oleh dokter kecil sebagai montoring kebersihan dan bebas dari jentik nyamuk. j) kerja bakti setiap 3 bulan sekali. k) lomba kebersihan kelas dalam satu tahun sekali. Hal ini juga dibuktikan dengan hasil observasi dan dokumentasi peneliti pada gambar berikut:

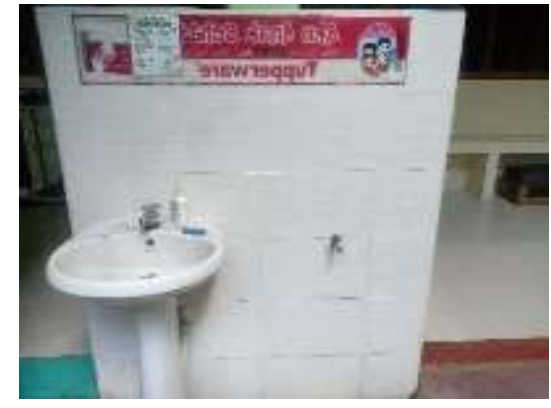

Gambar 3. Tempat Cuci Tangan

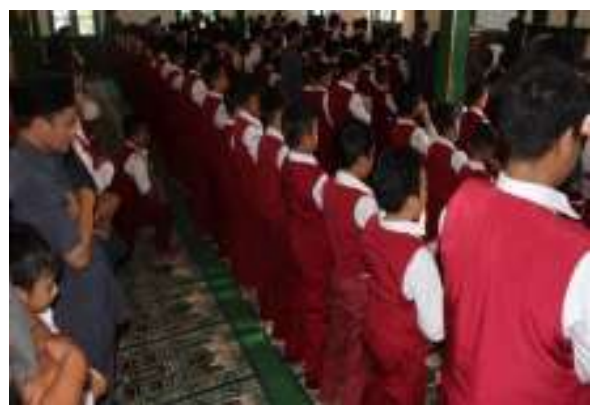

Gambar 5.Sholat Berjama'ah

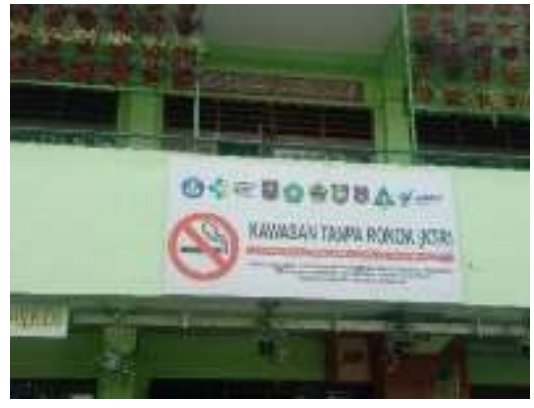

Gambar 4. Kawasan Bebas Rokok

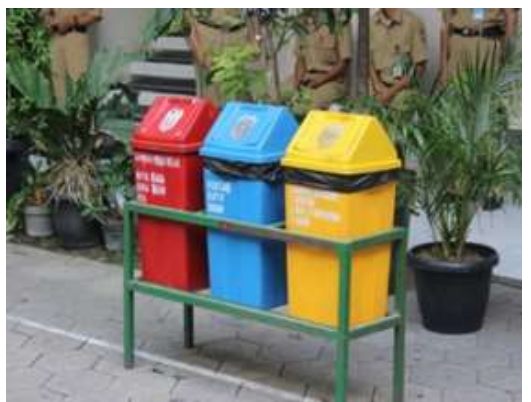

Gambar 6. Tempat sampah terpilah 
Penelitian yang sama dari Irwandi et al. (2016) menyebutkan bahwa banyak sekali program sekolah yang diguankan untuk menumbuhkembangkan kebiasaan hidup sehatpada seluruh warga sekolah terurama siswa. Penelitian pendukung lainnya oleh Taryatman (2016) menyebutkan bahwa untuk mengembangkan karakter anak muda dapat menerapkan beberapa indikator bersih dan sehat perilaku disekolah, yaitu mencuci tangan menggunakan air dan sabun, mengambil makanan sehat, tetap menjaga jamban agar bersih dan sehat, olahraga taratur, tidak merokok, membuang sampah ketempat sampah terdisaggregasi, pemberantasan jentik-jentik, timbang dan ukur tinggi, pertahankan rambut jadi bersih dan rapi, berpakaian bersih dan rapi, menjaga kuku agar bersih dan pendek. Selain itu, guru memiliki andil untuk menciptakan pembelajaran yang inovatif, dimana salah satunya diintegrasikan dengan penanaman pentingnya lingkungan yang bersih dan menjaga kesehatan diri. Pernyataan dari Minsih \& Galih (2018) mengatakan bahwa guru sebagai pengelola kelas inovatif seharusnya mampu menjadi motivator dan fasilitator penyampaian program sekolah kepada siswa. Sehingga pembiasaan tersebut sangat penting diterapkan pada siswa, guru, dan warga sekolah lainnya untuk mencapai budaya PHBS. Sekolah juga dapat menerapkan strategi untuk membudayakan siswa berperilaku hidup bersih maupun sehat.

Strategi yang digunakan agar siswa melaksanakan budaya PHBS diantaranya: Pertama, strategi menjalin kemitraan dengan orang tua agar dapat memantau perkembangan anak ketika dirumah, salah satunya tentang kemajuan anak dalam menjalankan hidup bersih dengan mengisi checklist pada buku monitoring yang diberikan sekolah. Kedua, kerjasama dengan UKS terkait penyuluhan tentang kesehatan seperti memberikan pelayanan, pendidikan, dan pembinaan kesehatan untuk warga sekolah.Ketiga, strategi dimana guru sering mengingatkan anak terkait PHBS. Penelitian relevan dari Apriani \& Gazali (2018) yang menunjukkan bahwa kemitraan dengan orang tua, kerjasama dengan UKS, dan adanya peran guru merupakan strategi sekolah untuk mewujudkan pembiasaan diri untuk siswa menerapkan PHBS. Sehingga sekolah merupakan wadah utama untuk membentuk karakter dan kepribadian siswa dalam menjaga kebersihan diri dan lingkungan serta pentingnya menjaga kesehatan. Menurut Rossi, Antún, \& Casagrande (2018) menyatakan bahwa lingkungan sekolah adalah salah satu lingkungan yang mampu menyediakan sarana untuk memajukan lingkungan hidup sehat dan membiasakannya dengan mengingat banyaknya waktu yang dihabiskan anak-anak di sekolah.

\section{Faktor yang Mempengaruhi Penerapan Budaya Sekolah dalam Mewujudkan Sekolah Sehat di SD Muhammadiyah 1 Ketelan Surakarta}

Beberapa faktor yang mempengaruhi penerapan budaya sekolah dalam mewujudkan sekolah sehat nasional di SD Muhammadiyah 1 Ketelan Surakarta yaitu faktor pendukung dan penghambat.Hasil wawancara faktor yang mempengaruhi budaya sekolah dalam mewujudkan sekolah sehat dapat dilihat pada tabel 2 .

Tabel 2. Ringkasan Hasil Wawancara Faktor yang Mempengaruhi Budaya Sekolah dalam Mewujudkan Sekolah Sehat Nasional

\begin{tabular}{|c|c|c|c|}
\hline \multirow[t]{2}{*}{ Aspek Pertanyaan } & \multicolumn{3}{|c|}{ Ringkasan Jawaban } \\
\hline & Informan Satu & Informan Dua & Informan Tiga \\
\hline $\begin{array}{lr}\text { Faktor } & \text { pendukung } \\
\text { budaya } & \text { sekolah } \\
\text { dalam mewujudkan } \\
\text { sekolah } \\
\text { nasional }\end{array}$ & $\begin{array}{l}\text { Faktor pendukung seperti memiliki } \\
\text { tenaga-tenaga ahli, sarana dan } \\
\text { prasarana yang memadai dan } \\
\text { dukungan dari semua pihak sekolah. }\end{array}$ & $\begin{array}{l}\text { Pendorong program } \\
\text { sekolah sehat yaitu sarana } \\
\text { dan prasarana, SDM yang } \\
\text { mumpuni dan } \\
\text { bekerjasama dengan } \\
\text { pihak luar sekolah seperti } \\
\text { Dinas Pertanian. }\end{array}$ & $\begin{array}{l}\text { Kerjasama antara semua } \\
\text { pihak sekolah dan wali } \\
\text { murid untuk menerapkan } \\
\text { PHBS sebagai budaya } \\
\text { sekolah dan menjalankan } \\
\text { program-program yang } \\
\text { telah disetujui bersama. }\end{array}$ \\
\hline \begin{tabular}{l}
\multicolumn{3}{l}{ Faktor } \\
penghambatan \\
budaya Sekolah \\
dalam mewujudkan \\
sekolah sehat \\
nasional
\end{tabular} & $\begin{array}{l}\text { Faktor penghambat yakni masih ada } \\
\text { pedangang yang masih berjualan } \\
\text { disekitar sekolah dan anak-anak } \\
\text { masih ada yang belum menerapkan } \\
\text { PHBS. }\end{array}$ & $\begin{array}{l}\text { Kurangnya pembiasaan } \\
\text { karena tidak semua orang } \\
\text { tua itu mampu } \\
\text { memberikan pembiasaan } \\
\text { PHBS kepada anaknya. }\end{array}$ & $\begin{array}{l}\text { Penghambatnya seperti } \\
\text { terkadang siswa sulit } \\
\text { dikendalikan seperti } \\
\text { membuang sampah } \\
\text { sembarangan dan masih } \\
\text { banyak pedagang yang } \\
\text { masih berjualan di area } \\
\text { sekolah. }\end{array}$ \\
\hline
\end{tabular}

Makna dari tabel 2 mengenai faktor-faktor yang mempengaruhi penerapan budaya sekolah dalam mewujudkan sekolah sehat nasional.Adapunpenjelasannya secara berturut-turut yaitu sebagai berikut:

a) Faktor pendukung penerapan budaya sekolah dalam mewujudkan sekolah sehat yaitu terdiri dari faktor internal dan eksternal. Pertama, faktor internal mencangkup Sumber Daya Manusia yang memadai dan sarana serta prasarana untuk memenuhi standar sekolah sehat. Adanya kesadaran diri dari setiap warga sekolah bahwa membiasakan Perilaku Hidup Bersih dan Sehat (PHBS) itu penting, akan sangat mendukung adanya 
program sekolah sehat. Selain itu secara prosedur, SD Muhammadiyah 1 Ketelan Surakarta juga sudah mempersiapkan tenaga pendidik yang bertanggungjawab atas program tersebut yaitu guru PJOK (Pendidikan jasmani, olahraga, dan kesehatan) berjumlah 6 orang, tenaga pembinaan UKS berjumlah 4 orang, petugas kebersihan, petugas pelaksana sekolah sehat sendiri. Maka, dengan adanya penanggungjawab yang jelas, program sekolah sehat dapat berjalan sesuai rencana. Penelitian yang sama dari Utama, Montessori, \& Indrawadi (2018) menyatakan bahwa salah satu faktor pendukung program sekolah sehat yaitu adanya kesadaran diri dan komitmen dari warga sekolah yang dibuktikan dengan adanya beberapa kegiatan pembinaan/penyuluhan terkait dengan PHBS. Penelitian dari Pradipta (2017) yang menyatakan bahwa faktor pendukung program sekolah sehat yaitu adanya komitmen dan dukungan dari seluruh pihak sekolah.sarana dan prasarana untuk memenuhi standar sekolah sehat. Program sekolah sehat akan berjalan jika fasilitas dan sarana \& prasarana sekolah yang memadai, seperti halnya: ruang guru, ruang kelas dan ruang UKS memiliki ventilasi udara yang cukup dan tersedianya alat kebersihan disetiap ruangan, tersedia tempat cuci, toilet yang bersih, halaman sekolah bersih dan tidak becek, dll. Hal tersebut sesuai dengan hasil observasi dan dokumentasi dari peneliti yang ditunjukkan pada gambar 1, gambar 2, gambar 3, gambar 4, dan gambar 6 . Penelitian yang sama dari Hermiyanty, Salmawati, \& Oktavian (2016) menyatakan bahwa ketersediaan fasilitas, sarana dan prasarana kebersihan sekolah dapat digunakan sebagai tolok ukur jalan atau tidaknya program sekolah sehat tersebut. Sekolah yang melaksanakan program sekolah sehat akan memiliki fasilitas kebersihan yang cukup baik serta pemenuhana sarana dan prasarana yang mendukung program tersebut. Penelitian serupa dari Samino, Ningrum, \& Sari (2020) membuktikan bahwa kurangnya sarana dan prasarana kebersihan sekolah dapat menjadi penyebab belum berhasilnya program sekolah bersih dan sehat.

Kedua, faktor eksternal yaitu bekerjasama dengan pihak luar yang mendukung program sekolah sehat baik orangtua siswa, Dinas Pertanian, Dinas Lingkungan Hidup, Dinas Kesehatan Kota, BPOM (Badan Pengawasan Obat \& Makanan), PMI (Palang Merah Indonesia) Cabang Kota Surakarta, Puskesmas Kecamatan Banjarsari, RS PKU Muhammadiyah, dan Fakultas Kedokteran Gigi UMS. Kerjasama tersebut dilakukan dengan tujuan untuk mengikut sertakan ahlinya dalam kegiatan program sekolah sehat, seperti halnya, memberikan sosialisasi, penyuluhan, maupun pelatihan terhadap siswa terkait dengan penerapan budaya sekolah dalam mewujudkan sekolah bersih dan sehat.Kegiatan tersebut dapat memberikan variasi untuk bentuk pelaksanaan program sekolah sehat di SD Muhammadiyah 1 Ketelan Surakarta supaya tidak monoton dan membosankan bagi siswa. Penelitian yang sama dari Manalu \& Suudi (2016) membuktikan bahwa adanya pelibatan dari pihak luar sekolah seperti Dinas Pendidikan dan Dinas Kesehatan sangat penting untuk menunjang program sekolah sehat, seperti halnya pengawasan terhadap jajanan sekolah, pembinaan dan mengedukasi peserta didik untuk menerapkan hidup sehat, ataupun kegiatan lainnya. Selain itu, pelibatan wali murid/orang tua dapat berupa pengawasan/pemantauan terhadap perilaku hidup sehat siswa ketika berada di rumah. Zubaidah, Ismanto, \& Sulasmono (2017) menyatakan bahwa program sekolah sehat dapat berjalan dengan baik apabila ada apresiasi dan partisipasi baik dari seluruh warga sekolah dan dapat bekerjasama dengan instansi/organisasi terkait.

b) Faktor penghambat penerapan budaya sekolah dalam mewujudkan sekolah sehat, diantaranya: pertama, kurangnya pembiasaan untuk berperilaku yang peduli kebersihan dan cinta akan kesehatan diri. Hal ini dikarenakan latar belakang siswa yang berbeda, sehingga intensitas pembiasaan diri untuk hidup bersih maupun sehat dari masing-masing orangtua juga berbeda satu sama lain. Sehingga disarankan, supaya sekolah dapat berkoordinasi denga wali murid/ orang tua terkait dengan pentingnya membudayakan perilaku hidup sehat baik disekolah maupun di rumah. Pernyataan dari Jatmika (2018) yang mengatakan bahwa melibatkan orang tua/walimurid dalam program sekolah merupakan bentuk dari menjaga hubungan/kemitraan antara sekolah dengan keluarga/orang tua/wali murid dari siswa.

Kedua, masih banyaknya pedagang jajanan yang berjualan diarea sekolah yang juga belum dapat dipastikan jajan yang dijualnya itu sehat atau tidak. Dalam hal ini, sekolah sangat disarankan bekerjasama dengan dinas kesehatan atau sejenisnya dalam melakukan pengawan terhadap jajan di area sekolah. Penelitian yang sama dari Manalu \& Suudi (2016) yang memberikan hasil bahwa masalah jajanan anak sekolah memerlukan kebijakan dari pusat seperti Badan POM, dan kementrian kesehatan untuk melakukan pengendalian terhadap jajanan anak sekolah. Pernyataan serupa dari Nurbiyati \& Wibowo (2014) yang mengatakan bahwa jajanan dapat berkontribusi paling tinggi dalam memberikan asupan nutrisi maupun energi dan zat gizi lainnya untuk anak di usia sekolah. Beliau juga menambahkan jajanan di sekolah yang jaminan kesehatannya masih kurang dapat menyebabkan gangguan pencernaan bahkan keracunan dan jika berlarut-larut akan mengakibatkan gizi buruk bagi anak. Selain itu, jajanan yang kurang baik dapat berdampak pada prestasi anak di sekolah.Sehingga jajanan yang dijual pada area sekolah sngat perlu diketahui kebersihan dan kandungan gizinya supayatidak berdampak buruk jika dikonsumsi siswa. 


\section{Peran Serta Siswa dalam Penyelenggaraan Sekolah Sehat Nasional di SD Muhammadiyah 1 Ketelan Surakarta}

Hasil penelitian terkait dengan peran serta siswa dalam penyelenggaraan sekolah sehat nasional di SD Muhammadiyah 1 Ketelan Surakarta, diantaranya: menjaga kebersihan lingkungan sekolah, kebersihan lingkungan kelas, dan kebersihan bagi setiap individu atau siswa. Berikut hasil wawancara tentang peran siswa dalam penyelenggaraan sekolah sehat nasional dapat dilihat pada tabel 3.

Tabel 3. Ringkasan Hasil Wawancara Peran Serta Siswa dalam Penyelenggaraan Sekolah Sehat Nasional

\begin{tabular}{lrlrl}
\hline \multicolumn{2}{c}{ Aspek Pertanyaan } & \multicolumn{4}{c}{ Ringkasan Jawaban } \\
\cline { 3 - 6 } & & \multicolumn{3}{c}{ Informan Satu } \\
Peran siswa & dalam & Program sekolah sehat telah Bersemangat mendukung dan \\
penyelenggaraan & sekolah & mampu membiasakan siswa untuk membiasakan diriberperilaku hidup \\
sehat nasional & & bertanggungjawab pada bersih dan sehat baik di kelas dan \\
& & kebersihan dan kenyamanan kelas lingkungan sekolah. Serta tahu cara \\
& maupun sekolah. Tercermin dari menjaga kebersihan diri sendiri seperti \\
& perilaku siswa yang cinta akan rajin memotong kuku, berpakaian rapi, \\
& PHBS. & dan makan makanan sehat. \\
\hline
\end{tabular}

Makna dari hasil wawancara tentang peran siswa dalam penyelenggaraan sekolah sehat nasional yaitu siswa bertanggungjawab untuk ikut andil dalam menjaga kebersihan kelas, lingkungan sekolah, dan mampu menjaga kebersihan diri sendiri seperti menjaga asupan makanannya, rajin memotong kuku, dan berpenampilan tetap rapi ketika di sekolah. Adapun penjelasan lebih rinci sebagai berikut: Pertama, menjaga kebersihan lingkungan sekolah.Siswa memiliki tanggungjawab penuh dalam menjaga kebersihan lingkungan sekolah, karena sekolah juga rumah bagi mereka untuk bermain sekaligus belajar bagi mereka. Aktivitas yang dilakukan siswa SD Muhammadiyah 1 Ketelan Surakarta dalam menjaga kebersihan sekolah, seperti halnya: membuang sampah di tempatnya dengan memisahkan antara sampah organik, plastik dan kertas, merawat tumbuhan yang ada di sekolah, membersihkan kamar mandi setelah digunakan. Sehingga sangat penting bagi mereka untuk menjaga kondisi sekolah tetap bersih dan nyaman. Pernyataan yang sama dari Hermiyanty et al. (2016) mengatakan bahwa sekolah dimana warganya secara terus menerus membiasakan diri untuk PHBS akan memiliki lingkungan sekolah yang bersih, nyaman, dan aman.

Kedua, kebersihan lingkungan kelas.Siswa juga memiliki kewajiban untuk menjaga kebrsihan lingkungan kelasnya masing-masing.Caranya yaitu adanya pembagian piket untuk membersihkan kelas baik sebelum memulai maupun sesudah pembelajaran. Sebelum maksudnya kelas sudah bersih ketika akan memulai pelajaran, sehingga siswa dalam belajar dalam kondisi bersih dan nyaman. Sedangkan setelah maksudnya, ketika akan pulang sekolah, kelas sudah dalam kondisi bersih dan rapi. Menurut Seyaningati, Akbar, \& Mahanani (2020) menyatakan bahwa kegiatan piket kelas merupakan bagian dari pembelajaran karakter bagi siswa untuk peduli lingkungan yang diterapkan oleh sekolah negeri di Indonesia. Penelitian yang sama dari Kartika \& Wiguna (2020) menyatakan bahwa melaksankan tugas piket kelas sesuai jadwal juga bagian dari pelaksanaan kedisiplinan sebagai bekal pembentukan nilai karakter pada siswa. Sehingga piket kelas tidak hanya membuat siswa nyaman dalam proses belajar mengajar, tetapi juga membentuk kedisiplinan dan karakter siswa menjadi lebih baik.

Ketiga, kebersihan untuk diri sendiri atau masing-masing diri siswa. Hal ini penting dilakukan oleh siswa terlebih dahulu sebelum menjalankan peran yang lainnya, seperti halnya: siswa selalu mencuci tangan di wastafel yang sudah disediakan baik sebelum maupun sesudah beraktivitas, selalu memelihara kerapian rambut, memelihara kebersihan kuku dengan rajin memotong kuku, tidak makan makanan yang banyak mengandung bahan pengawet dan tidak jajan diluar sekolahan, selalu menerapkan slogan-slogan yang tertempel di setiap tembok. Penelitian yang sama dari Banun (2016) yang menyatakan bahwa dasar indikator pengetahuan PHBS pada siswa dapat dilihat melalui bagaimana siswa menjaga kebersihan kuku, kebersihan mata, dan juga menggunakan air bersih. Penelitian Fatmawati (2019) yang menyatakan bahwa beberapa masalah kesehatan yang di alami siswa sekolah dasar yaitu berhubungan dengan kebersihan diri/personal hygiens anak dan lingkungan, seperti halnya menggosok gigi yang sesuai, kebiasaan cuci tangan menggunakan sabun dan air mengalir, serta kebersihan diri. Beliau menyarankan terhadap pihak sekolah khususnya guru dan petugas UKS untuk dapat mendorong siswa dan meningkatkan pengetahuan serta pemahamannya terhadap pentingnya kebersihan diri.

\section{SIMPULAN DAN SARAN}

Berdasarkan pemaparan terkait budaya sekolah dalam mewujudkan sekolah sehat nasional di SD Muhammadiyah 1 Ketelan Surakarta, diantaranya: Pertama 4 komponen kebijakan penting yang diambil yaitu mengembangkan kebijakan sekolah peduli dan berwawasan lingkungan, implementasi kurikulum berbasis 
kesehatan dan berbudaya lingkungan, mengembangkan kegiatan berbasis partisipatif, pengelolaan dan mengembangkan sarana prasarana pendukung program sekolah sehat. Kedua, Partisipasi aktif dari seluruh pihak dalam mewujudkan sekolah sehat nasional baik pihak dalam dan luar sekolah. Ketiga, Program pendukung oleh SD Muhammadiyah 1 Ketelan Surakarta untuk mewujudkan sekolah sehat, diantaranya: UKS (Unit Kesehatan Sekolah), Kantin Sehat, E- Money, bank sampah, Green House dan BUMS. Keempat, pengintegrasian budaya sekolah dalam mencapai sekolah sehat nasional tercermin dengan adanya budaya tolong, maaf, terima kasih, $7 \mathrm{~K}$ dan PHBS. Kelima, kebiasaan siswa yang mencerminkan sekolah sehat dan peduli lingkungan hidup. Serta Strategi agar siswa melaksanakan budaya PHBS.

Faktor yang mempengaruhi penerapan budaya sekolah dalam mewujudkan sekolah sehat yaitu Faktor pendukung terdiri sumber daya manusia yang aktif dan sarana prasarana untuk memenuhi standar sekolah sehat, bekerjasama dengan pihak luar baik orangtua siswa, Dinas Pertanian, Dinas Lingkungan Hidup, dan Dinas Kesehatan, BPOM (Badan Pengwasan Obat \&Makanan), Dinas Kesehatan Kota, dll. Sedangkan faktor penghambat terdiri dari kurangnya pembiasaan dalam menerapkan perilaku hidup bersih dan sehat, masih banyaknya pedagang jajanan yang berjualan diarea sekolah yang juga belum dapat dipastikan jajan tersebut sehat atau tidak. Peran serta siswa dalam penyelenggaraan sekolah sehat nasional terdiri dari menjaga kebersihan lingkungan sekolah, kebersihan lingkungan kelas, dan kebersihan setiap individu seperti rajin meotong kuku dan berpenampilan rapi.

\section{DAFTAR RUJUKAN}

[1] Apriani, L., \& Gazali, N. 2018. Pelaksanaan trias usaha kesehatan sekolah (UKS) di sekolah dasar. Jurnal Keolahragaan, 6(1), 20-28. https://doi.org/10.21831/jk.v6i1.14456

[2] Banun, T. S. 2016. Hubungan antara Pengetahuan PHBS dengan Pola Hidup Sehat Siswa di SD Tamanan. Jurnal Pendidikan Guru Sekolah Dasar, 5(14), 1378-1386.

[3] Budiarti, A., \& Sriawan, S. 2017. Penerapan budaya 7K untuk siswa sekolah dasar. Jurnal Pendidikan Jasmani Indonesia, 13(1), 25-32. https://doi.org/10.21831/jpji.v13i1.21025

[4] Bur, N., \& Septiyanti. 2020. Perilaku Hidup Bersih Dan Sehat ( PHBS ) di SD Inpres Katangka Gowa. Celebes Abdimas: Jurnal Pengabdian Kepada Masyarakat, 2(1), 32-41.

[5] Creswell, J. W. 2014. Research Design: Qualitative, Quantitative, and Mixed Methods Approaches, 2014

[6] Cvencek, D., Fryberg, S. A., Covarrubias, R., \& Meltzoff, A. N. 2017. Self-Concepts, Self-Esteem, and Academic Achievement of Minority and Majority North American Elementary School Children. Child Development, 89(4), 1099-1109. https://doi.org/10.1111/cdev.12802

[7] Fatmawati, T. Y. 2019. Meningkatkan Personal Hygiena pada Siswa SD Negeri Kecamatan Kota Baru. Jurnal Abdimas Kesehatan (JAK), 1(1), 12. https://doi.org/10.36565/jak.v1i1.4

[8] Hermiyanty, Salmawati, L., \& Oktavian, F. 2016. Evaluasi Implementasi Program Sekolah Dasar Bersih Dan Sehat Di Kota Palu. Jurnal Preventif, 7, 13-20.

[9] Hidayatullah. 2016. Implementasi Program Adiwiyata di SD Islam Al- Azhar 29 BSB Semarang. In Skripsi UIN Walisongo Semarang.

[10] Irwandi, S., Ufatin, N., \& Sultoni. 2016. Peran Sekolah Dalam Menumbuhkembangkan Perilaku Hidup Sehat pada Siswa Sekolah Dasar (Studi Multi Situs di SD Negeri 6 Mataram dan SD Negeri 41 Mataram Kota Mataram Nusa Tenggara Barat). Jurnal Pendidikan, 1 (3), 492-498. http://journal.um.ac.id/index.php/jptpp/article/view/6178

[11] Jatmika, S. 2018. Pelaksanaan Kemitraan antara Sekolah, Keluarga, dan Masyarakat pada smk bisnis manajemen kota surakarta. Jurnal Pendidikan Dan Ilmu Sosial, 28(2), 36-43.

[12] Kandou, G. D., \& Caroline, P. 2019. Improving Students Knowledge of Clean and Healthy Living Behavior through Health Education. Proceedings of the 3rd Asian Education Symposium (AES 2018), 253(Aes 2018), 412-416. https://doi.org/10.2991/aes-18.2019.94

[13] Kartika, S., \& Aditia Wiguna, F. 2020. Implementasi Kedisiplinan Di Sdn Sukorame 2 Sebagai Bekal Membentuk Pendidikan Karakter Pada Siswa. Jurnal Pendidikan Dasar Nusantara, 6(1), 163-173. https://doi.org/10.29407/jpdn.v6i1.14439

[14] Kusumawardani, L. H., Rekawati, E., \& Fitriyani, P. 2019. Improving diarrhoeal and clean and healthy living behaviour (PHBS) through collaboration socio-dramatic play (Ko-Berdrama) in school age children. Sri Lanka Journal of Child Health, 48(3), 240-245. https://doi.org/10.4038/sljch.v48i3.8759

[15] Lee, A., St Leger, L. H., Ling, K. W. K., Keung, V. M. W., Lo, A. S. C., Kwong, A. C. M., Ma, H. P. S., \& Armstrong, E. S. 2018. The Hong Kong Healthy Schools Award Scheme, school health and student health: An exploratory study. Health Education Journal, 77(8), 857-871. https://doi.org/10.1177/0017896918779622 
[16] Lee, M., \& Louis, K. S. 2019. Mapping a Strong School Culture and Linking it to Sustainable School Improvement. Teaching and Teacher Education, 81, 84-96. https://doi.org/10.1016/j.tate.2019.02.001

[17] Manalu, H. S. P., \& Suudi, A. 2017. Kajian Implementasi Pembinaan Pangan Jajanan Anak Sekolah (PJAS) untuk Meningkatkan Keamanan Pangan: Peran Dinas Pendidikan dan Dinas Kesehatan Kota. Media Penelitian Dan Pengembangan Kesehatan, 26(4), 249-256. https://doi.org/10.22435/mpk.v26i4.5734.249256

[18] Maryamah, E. 2016. Pengembangan Budaya Sekolah. Tarbawi, 2(02), 86-96. https://doi.org/10.1177/003693307301800103

[19] Minsih, M., \& D, A. G. 2018. Peran Guru Dalam Pengelolaan Kelas. Profesi Pendidikan Dasar, 1(1), 20. https://doi.org/10.23917/ppd.v1i1.6144

[20] Nurbiyati, T., \& Wibowo, A. H. 2014. Pentingnya Memilih Jajanan Sehat Demi Kesehatan Anak. Jurnal Inovasi Dan Kewirausahaan, 3(3), 192-196. https://journal.uii.ac.id/ajie/article/view/7832

[21] Pradipta, H. N. 2017a. Implementasi Program Sekolah Sehat Di Sd N Tegalrejo 1 Yogyakarta. Jurnal Kebijakan Pendidikan, Vol. VI(1), 20-28.

[22] Pradipta, H. N. 2017b. Implementasi Program Sekolah Sehat Di SDN Tegalrejo 1 Yogyakarta. Jurnal Kebijakan Pendidikan, Vol. VI(1), 20-28.

[23] Rochmah, K. N. 2018. Pelaksanaan Usaha Kesehatan Sekolah (UKS) di SD 1 Bantul. Jurnal Pendidikan Guru Sekolah Dasar, 22(7), 2.142-2.153.

[24] Rokhani, C. T. S. 2020. Best Practice Implementasi Program Sekolah Adiwiyata Nasional Sekolah Dasar Sasaran Kurikulum 2013 di SDN Degkek 01 Pati. Journal Industrial Enginering \& Management Research, 1(2), 184-194.

[25] Rossi, M., Antún, M., \& Casagrande, M. . et al. 2018. Evaluation of the Intervention of the My Healty Program in a Cohort of School that has Participated During 2016-2017. Revista de La Facultad de Ciencias Médicas, 76(1), 37-46.

[26] Samino, Ningrum, D. A. W., \& Sari, S. D. R. 2020. Evaluasi Program Sekolah Dasar Bersih dan Sehat: Studi Pada Madrasah Ibtidaiyah di Kota Bandar Lampung. Jurnal Dunia Kesehatan Masyarakat, 9(3), 423433.

[27] Sdmuh1solo.com. 2019a. Dinobatkan Sekolah Sehat Terbaik Tingkat Jawa Tengah. https://www.sdmuh1solo.com/2019/11/dinobatkan-sekolah-sehat-terbaik.html

[28] Sdmuh1solo.com. 2019b. Sri Sayekti Ajak Hidup Sehat dan Berprestasi. https://www.sdmuh1solo.com/2019/12/sri-sayekti-ajak-hidup-sehat-dan.html

[29] Sdmuh1solo.com. 2020. Ganjar Pranowo Berikan Dukungan Sekolah Sehat Nasional. https://www.sdmuh1solo.com/2020/03/ganjar-pranowo-berikan-dukungan-sekolah.html

[30] Seyaningati, M., Akbar, S., \& Mahanani, P. 2020. Pembelajaran Pendidikan Karakter Peduli Lingkungan melalui Program Adiwiyata di SDN Bunulrejo 2 Kota Malang. Jurnal Pendidikan Dasar Nusantara, 6(1), 84-102.

[31] Sugiyono. 2015. Metode Penelitian. Alfabeta.

[32] Sulastri, K., Purna, I. N., \& Suyasa, I. N. G. 2014. Hubungan Tingkat Pengetahuan Dengan Perilaku Anak Sekolah Tentang Hidup Bersih Dan Sehat Di Sekolah Dasar Negeri Wilayah Puskesmas Selemadeg Timur Ii. Journal of Environmental Health, 4, 99-106.

[33] Taryatman. 2016. Budaya Hidup Bersih dan Sehat di Sekolah Dasar untuk Membangun Generasi Muda yang Berkarakter. Trihayu: Jurnal Pendidikan Ke-SD-An, 3(1), 8-13. https://media.neliti.com/media/publications/259042-budaya-hidup-bersih-dan-sehat-di-sekolahe30972f8.pdf

[34] Utama, R. T., Montessori, M., \& Indrawadi, J. 2018. Pelaksanaan Sekolah Sehat di SMP Negeri 24 Padang. Journal of Civic Education, 1(3), 242-249. https://doi.org/10.24036/jce.v1i3.225

[35] Vivas, A. P., Gelaye, B., Aboset, N., Kumie, A., Berhane, Y., \& Williams, M. A. 2010. Knowledge, attitudes and practices (KAP) of hygiene among school children in Angolela, Ethiopia. Journal of Preventive Medicine and Hygiene, 51(2), 73-79. https://doi.org/10.15167/2421-4248/jpmh2010.51.2.216

[36] Wiwik, K., Purnamasari, I., \& Damayani, A. T. 2016. Penguatan Kultur Sekolah Untuk Mewujudkan Pendidikan Ramah Anak. Jurnal Cakrawala Pendidikan, 1(1), 125-133. https://doi.org/10.21831/cp.v1i1.8383

[37] Yufiarti, Y., Edwita, \& Suharti. 2019. Health Promotion Program (JUMSIH); To Enhance Children's Clean and Healthy Living Knowledge. JPUD-Jurnal Pendidikan Usia Dini, 13(2), 341-355. https://doi.org/10.21009/jpud.132.10

[38] Zubaidah, S., Ismanto, B., \& Sulasmono, B. S. 2017. Evaluasi Program Sekolah Sehat Di Sekolah Dasar Negeri. Kelola: Jurnal Manajemen Pendidikan, 4(1), 72. https://doi.org/10.24246/j.jk.2017.v4.i1.p72-82 
Vilian, M. T., Minsih. (2021) Jurnal Pendidikan Dasar Flobamorata. Vol. 2 (1) hal. 152-161. 